\title{
A Different Pontic Design for Fiber-Reinforced Composite Bridgeworks: A Clinical Report
}

\author{
Ovul Kumbuloḡlua, DDS, PhD \\ Niler Özdemira, DDS \\ Gökhan Aksoy', DDS, PhD \\ Atilla User ${ }^{c}, \mathrm{DDS}, \mathrm{PhD}$
}

\section{ABSTRACT}

Objectives: This clinical report describes a relatively simple but esthetic, non-invasive and functional prosthodontic treatment option for a patient with missing tooth.

Methods: A patient with a missing maxillary left canine was non-invasively treated with a fiber reinforced composite (FRC) bridgework with an all ceramic (Empress II, Ivoclar Vivadent, Schaan, Liechtenstein) pontic design, using laboratory technique.

Results: The restoration has served the patient for 2 year, seemingly without discomfort, and it has not required any maintenance. The patient has kept up with his oral hygiene.

Conclusions: Although additional clinical experience is necessary, fiber-reinforced composite materials can be used in combination with a lithium disilicate ceramic material in fixed partial dentures. (Eur J Dent 2007,1:50-53)

Key words: Fiber-reinforced composite bridgeworks; All ceramic pontic; Indirect application.

\section{INTRODUCTION}

Restoring a number of missing teeth is usually a difficult problem for the clinician. Position and size of teeth, amount of space, general health, economical conditions and patient's expectations should be considered when choosing the appropriate material and technique.

It is obvious that, application of a minimally invasive technique to provide the restoration through minimum or no preparation on neighboring sound teeth is the most preferable choice. Dental implants or adhesive techniques can be used in such applications.'

With the development of adhesive technique

$\square$ a Research Associate, Department of Prosthodontics, School of Dentistry, Ege University, Izmir, Turkey

${ }^{\mathrm{b}}$ Associate Professor, Department of Prosthodontics,

School of Dentistry, Ege University, Izmir, Turkey

Professor, Department of Prosthodontics,

School of Dentistry, Ege University, Izmir, Turkey

$\square$ Corresponding author: Niler ÖZDEMIR,

Department of Prosthodontics School of Dentistry

Ege University Bornova, 35100 Izmir / Turkey

Phone: +902323880327

Fax: +902323885040

E-mail: nilerozdemirdagmail.com for bonding composite resin micromechanically to etched enamel, resin bonded fixed partial dentures (FPDs) became an alternative to full-preparation fixed partial dentures. The intention with this alternative application is to preserve healthy tooth substance with a minimal invasive and reversible treatment based on using not only metalfree materials to substitute alloys, but also having the material to be used in the dynamic treatment approach. FRC applications are an alternative treatment in adhesive techniques. ${ }^{2,3}$

The higher debonding rate of long-span resinbonded FPDs than those with one pontic can be caused by the increased tensile stress at the bonding surface by the transfer of the occlusal loads from the rigid cast metal framework. ${ }^{4}$ From this perspective, a framework material with a lower elastic modulus would be beneficial to reduce the stress level at the interface of luting cement and tooth. A framework material with better bonding properties to the composite luting cements than that obtained with metal alloys might also decrease the number of debondings of resin-bonded FPDs. ${ }^{5}$

The combination of glass fiber reinforced composite resin with ceramics is considered to be an 
alternative for anterior bridgeworks. The popularity of all-ceramic restorations has increased in recent years. Among many ceramics, a lithium disilicate glass ceramic core veneered with sintered glass ceramic (Empress II, Ivoclar Vivadent, Schaan, Liechtenstein) exhibits a strength that has been suggested to be high enough for the fabrication of short-span fixed partial dentures. ${ }^{6,7}$

This clinical report describes a the rehabilitation of a referred patient with a missing maxillary left canine, which was non-invasively restored using a FRC bridgework with a lithium disilicate glass ceramic core veneered with sintered glass ceramic (Empress II, Ivoclar Vivadent, Schaan, Liechtenstein) pontic design, using indirect technique.

\section{CASE REPORT}

A 29-year-old male patient referred to our clinic with loss of aesthetics and function because of a missing maxillary left canine (Figure 1). Following detailed clinical and radiographic examinations and receiving patient's uneventful medical history, a FPD rehabilitation made with glass FRC and an all ceramic pontic design, which does not necessitate any preparation on abutment teeth and would be satisfactory both esthetically and functionally, was considered to be the ideal treatment approach for the patient. After having consent of the patient, maxillary and mandibular impressions were made with silicone based impression mate-

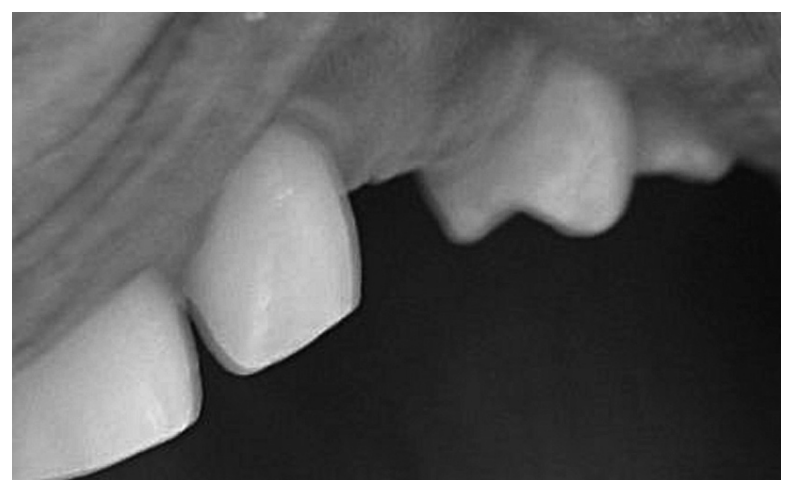

Figure 1. Missing maxillary left canine.

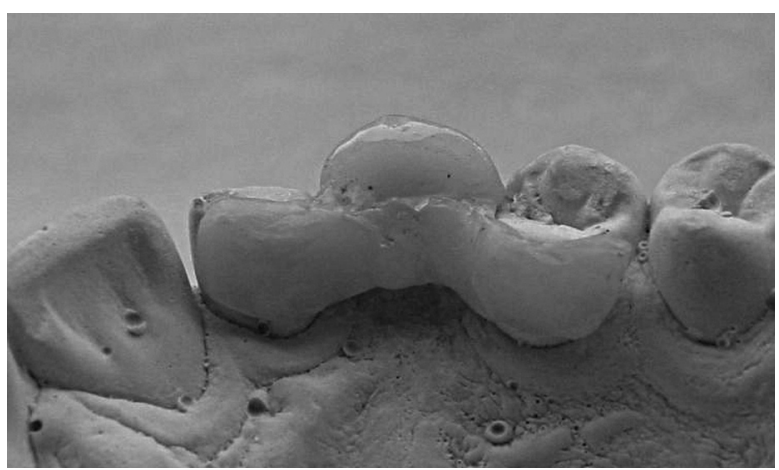

Figure 3. Palatinal appearance of adhesive bridgework on the diagnostic cast. rial and then cast models were prepared in the laboratory. A glass ceramic core veneered with sintered glass ceramic (IPS Empress II, Ivoclar Vivadent, Schaan, Liechtenstein) pontic was designed and fabricated for the missing tooth on the cast model (Figure 2). A silicone key was prepared in order to give the ceramic pontic its correct position. To provide the adhesion of ceramic to glass fiber material and composite resin, bonding surface of the ceramic pontic was $9.5 \%$ hydrofluoric acid etched (Ultradent, USA) for $1 \mathrm{~min}$. After rinsing and air-drying, silane coupling agent (Monobond, Ivoclar Vivadent, Schaan, Liechtenstein) was applied over the surface and left to dry for $1 \mathrm{~min}$. It was followed by the application of bonding agent (Heliobond, Ivoclar Vivadent, Schaan, Liechtenstein), distribution over the surface of pontic by air spray and light-polymerization with a light curing device (Elipar Freelight, 3M ESPE, USA) for $40 \mathrm{sec}$. A thin layer of flowable composite resin (Filtek Flow, 3M ESPE, USA), together with the polymer resin-impregnated uni-directional glass fiber reinforcement material (EverStick C\&B, Stick Tech, Finland) was applied to the palatinal surfaces of the adjacent teeth on the isolated model together with the ceramic pontic and they were both lightpolymerized through steps for 40 secs. The outer surface of glass fiber was covered with a thin layer of flowable composite and light-polymerized for 40 secs from each aspect. Following finishing and polishing procedures, the fiber bridgework was

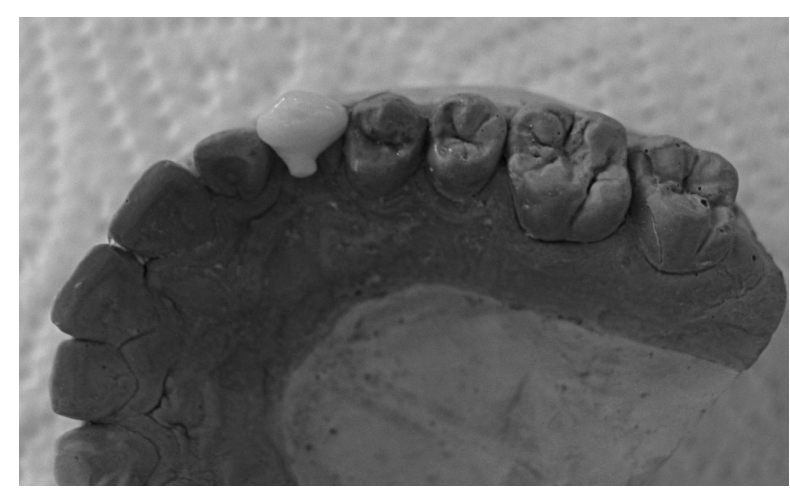

Figure 2. Full ceramic pontic placed on the diagnostic cast.



Figure 4. Buccal appearance of fiber reinforced adhesive restoration on the cast. 
controlled in the patient's mouth and it was continued with cementation procedures (Figures 3, 4). Bonding surfaces of the wings of FRC bridgework were roughened using a stone bur with low-speed handpiece. Bonding surfaces of the restoration were covered with the bonding agent (Heliobond, Ivoclar Vivadent, Schaan, Liechtenstein) and kept in a dark place for $5 \mathrm{~min}$. Meanwhile, the abutment teeth were cleaned with pumice using a prophylaxy brush on a low-speed handpiece. The restoration was cemented with dual-cure composite resin luting cement (Variolink II, Ivoclar Vivadent, Schaan, Liechtenstein) according to manufacturer's directions and light-polymerized from each aspect for $40 \mathrm{sec}$. Following controls for occlusal adjustment, self-assessment of oral hygiene was described and recalled periodically.

A satisfactory result for the patient was reached both aesthetically and functionally (Figures 5-7).

\section{RESULTS}

The appliance has served the patient well and immensely increased his quality of life. It has given him normal smiling abilities. By means of a thorough follow-up and good cooperation, this device has served the patient without any repair or adjustment for 2 year (Figure 8). The patient has been clinically followed on a periodical basis.

\section{DISCUSSION}

Many materials, methods and techniques for reinforcing composite resins to bond a pontic onto abutment teeth have been tried and promoted. Almost all approaches for reinforcing composite resins, such as metal bars, wires, screen, fishing line or fiberglass and using a denture tooth for the



Figure 5. Cemented restoration in the mouth.

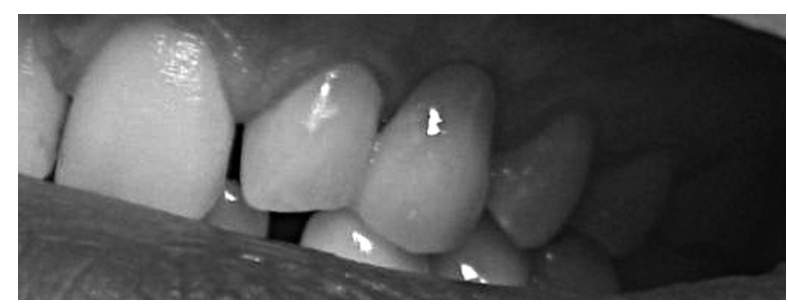

Figure 6. Clinical view of restoration from labial aspect. pontic have been successful to varying degrees. These groups of materials are never without compromising esthetics or the liberal cutting of tooth structure to gain mechanical advantage. Many ideas to increase the bulk of the resin material to cover the strengthening insert lead to hygiene problems. Flexing of the bridge cracks the composite at the interproximal bond to the abutment teeth and over the reinforcing agent at the interface with the denture tooth pontic. ${ }^{8} \mathrm{~A}$ combination of glass fiber with all-ceramic pontic was applied in this case. A satisfactory result was obtained both esthetically and functionally.

The esthetical properties of the FPD with translucent FRC framework were considerably superior to that of FPDs with a metal framework as analyzed subjectively by the dentists. In addition, the possibility of extending the bonding wings of the FPD even to the labial/buccal surface of the abutment without causing esthetic problems seems to offer new possibilities in FPD treatment. ${ }^{5}$ Using minimal invasive treatment, treatment costs can be lowered to some extent. In some instances, the cost of a treatment with fixed glass FRC restoration may cost as low as an acrylic removable partial denture. ${ }^{9}$ According to clinical 5.25 year follow-up studies, the success rate was found to be $76 \%$ for metal adhesive bridgeworks while it was $93 \%$ for FRC FPDs for the same duration. ${ }^{10}$

A good level of oral hygiene is of great importance with surface-retained adhesive restorations even a thin layer of fiber reinforced composite material is adhered to the tooth surface. The marginal regions are potential sites for oral microbes to attach and grow. It is therefore recommended to contour the marginal areas of the bonding wings after cementation by grinding and polishing. This enables effective plaque control.?

The indirect technique of producing multiple units of fiber reinforced laboratory fabricated restorations readily ensures for the perfection of occlusal contour and contacts, and proximal contact areas that can be contoured into the required emerging profile of the restoration. ${ }^{11}$

Since glass fiber fixed partial dentures have esthetic and economic superiorities, are easy to repair and require no preparation on sound teeth,

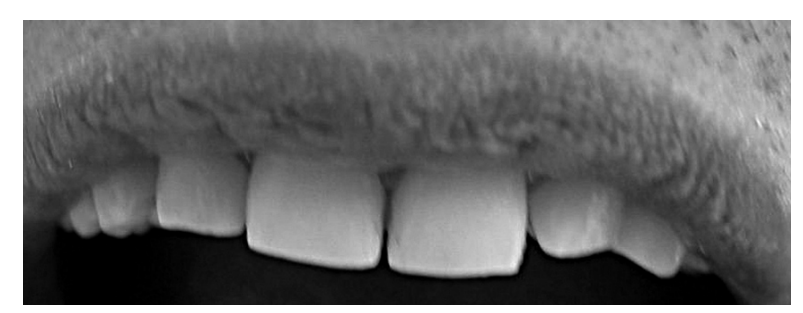

Figure 7. Two year follow-up intraoral view of the restoration. 
they present an alternative treatment choice both for patient and the clinician. ${ }^{11,12}$ However, the procedure is highly operator dependent and demands appropriate case selection and precise technique. The long-term behavior of the combination of glass fibers with all ceramic pontics must be evaluated in clinical studies.

\section{REFERENCES}

1. Leal FR, Cobb DS, Denhy GE, Margeas RC. A conservative aesthetic solution for a single anterior edentulous space: one-year follow-up. Pract Proced Aesthet Dent 2001;13:635641.

2. Brunton PA. Fiber-reinforced composite fixed partial dentures: initial experiences. In: Vallittu PK (ed). The third international symposium on fiber-reinforced plastics in dentistry Manchester, England, 2002:7-14.

3. Vallittu PK. Prosthodontic treatment with a glass fiber-reinforced resin-bonded fixed partial denture: a clinical report. J Prosthet Dent 1999;82:132-135.

4. Philiph RW. Skinner's science of dental materials. 9th ed. Philadelphia: WB Saunders 1991:373-375.

5. Vallittu PK. Resin-bonded, glass fiber-reinforced composite fixed partial dentures: a clinical study. J Prosthet Dent 2000;84:413-418.

6. Culp L. Empress 2. First year clinical results. J Dent Tech 1996;16:12-15.

7. Narcisi EM. Three-unit bridge construction in anterior single-pontic areas using a metal-free restorative. Compend Contin Educ Dent 1999;20:109-120.

8. Belvedere PC. Single-sitting, fiber-reinforced fixed bridges for the missing lateral or central incisors in adolescent patients. Dent Clin North Am 1998:4:665-682.

9. Vallittu PK. Fiber-reinforced composites in fixed prosthodontics-aspects on tooth replacement and maintenance care. In: Vallittu PK (ed). The third international symposium on fiber-reinforced plastics in dentistry. Manchester, England, 2002:24-30.

10. Vallittu PK. Survival rates of resin-bonded, glass fiber composite fixed partial dentures with a mean follow-up of 42 months: a pilot study. J Prosthet Dent 2004;91:241-246.

11. Glyn TD. Optimal fiber reinforcement techniques in multiple unit laboratory composite restoration designs. The third international symposium on fiber-reinforced plastics in dentistry. In: Vallittu PK (ed) Manchester, England, 2002: 51-62.

12. Husein A, Berekally T. Indirect resin-bonded fibre-reinforced composite anterior bridge: A case report. Aust Dent $J$ 2005;50:114-118. 